\title{
A ANOMALIA DA POLÍTICA DE CIÊNCIA E TECNOLOGIA*
}

\section{Renato Dagnino}

\section{Introdução}

Este trabalho sintetiza o conteúdo das três seções iniciais do relatório da pesquisa $A$ anomalia $d a$ politica de C\&T e sua atipicidade periférica: o caso brasileiro, cujas partes são: 1) "Políticas 'normais': processo decisório: atores, agendas, projeto político"; 2) "Políticas anômalas"; 3) "A anomalia da PCT"; 4) "A anomalia da PCT brasileira"; 5) "A atipicidade da PCT brasileira". Atravessando ideologias e reunindo desde neoliberais a marxistas ortodoxos, o que aqui se caracteriza como o mito da Neutralidade e do Determinismo da Tecnociência esses mitos fazem com que os projetos políticos dos

* Agradeço aos colegas do Grupo de Análise de Políticas de Inovação da Unicamp e aos pareceristas da revista pelas observaçōes a versões anteriores deste trabalho.

Artigo recebido em 29/10/2013

Aprovado em 24/02/2014 atores envolvidos com a política de ciência e tecnologia (PCT) - em especial, daqueles que se alinham com os interesses da classe trabalhadora - não se expressem em suas agendas particulares e, em consequência, na agenda decisória que origina a PCT como política pública. Por essa agenda decisória estar enviesada pela concepção da neutralidade e do determinismo da tecnociência, que considera a tecnociência (produzida pelas e para as empresas) passível de ser "usada" para a materialização de qualquer projeto político, a PCT, mesmo quando elaborada por governos de esquerda, tende a estar a serviço dos valores e interesses do capital.

Após a caracterização da anomalia da PCT, a pesquisa comenta evidências discursivas que mostram como ela se manifesta na PCT brasileira. Em seguida, expõe o argumento acerca da atipicidade da PCT periférica, que pode ser inferido diretamente das contribuições dos fundadores do Pensamento Latino-americano em Ciência, Tecnologia e 
Sociedade (PLACTS) (Dagnino, Thomas e Davyt, 1996), que há mais de quatro décadas apontaram a diferença entre o comportamento das empresas dos países de capitalismo avançado (daqui para frente, países avançados) e o das aqui localizadas. Ao explicaram sua baixa propensão a realizar pesquisa e desenvolvimento (P\&D) em função de nossa condição periférica, mostraram, por um lado, que nossa PCT dificilmente poderia alterá-la e, por outro, que para colocar em ação nosso potencial tecnocientífico eram necessárias substantivas mudanças no plano político e socioeconômico.

Evidências concernentes à experiência brasileira permitem hoje comprovar esse comportamento sensivelmente distinto do visado pela PCT orientada pelo modelo institucional ofertista linear, criticado pelo PLACTS e, mais recentemente, pelo postulado pela Economia da Inovação, ambos inspirados na realidade e nas experiências de modelização da relação entre ciência, tecnologia e sociedade (CTS) e de elaboração da PCT dos países avançados.

Ao mesmo tempo que mostram a correção da formulação do PLACTS, essas evidências revelam o irrealismo das expectativas dos fazedores da PCT que tentam mudar o comportamento das empresas locais, considerado irracional e atrasado. Quando se reinterpreta essa formulação à luz da noção de anomalia genérica da PCT, chega-se a uma caracterização bem distinta daquilo que ela considerava os obstáculos ao cenário de equidade e justiça social que pretendia. Fica evidente que o caráter comportamental adverso ao cenário que ela considerava desejável não era exclusivo à maneira (atípica e específica) como a condição periférica atuava sobre os empresários locais. Vem à tona o condicionamento que exerce sobre a atuação da comunidade de pesquisa a concepção da neutralidade e do determinismo da tecnociência - da qual decorre a anomalia (genérica) da PCT.

Kuhn (1978) chama de anomalias os problemas não solucionados ou os fenômenos não explicados que a teoria vai apresentando à medida que é empregada pelos pesquisadores. Segundo ele, "as anomalias aparecem somente contra o pano de fundo proporcionado pelo paradigma da ciência normal" (Idem, p. 192). A noção de política anômala deriva, justamente, da dificuldade encontrada por um analista da PCT que se pretende multidisciplinar para apreender o fenômeno participação dos atores no seu processo decisório. Em especial, de entender como ocorre essa participação em vista da relação entre ela e o conceito de projeto político, que estabelece o "paradigma normal" da ciência política.

O fato de que, novamente de acordo com Kuhn (1978), as anomalias podem ser resolvidas com o avanço da própria "ciência normal" - e que seja apenas quando elas se acumulam a ponto de competir com a "ciência normal" que pode ocorrer uma revolução científica - coloca em seus devidos termos incrementais a modesta intenção que motivou a formulação da noção aqui apresentada.

Como o leitor pode observar pelo conteúdo dos trabalhos que resultam de pesquisas sobre a PCT com os quais me envolvi (e que cito para indicar a origem das minhas afirmações), minha familiaridade com a temática que trato aqui era muito escassa quando comecei a tentar sistematizar, apoiado na literatura de ciência política, o que eu percebia na PCT como o que vim a chamar de anomalia. Minha expectativa com este trabalho, pensando nos colegas de disciplina (uma vez que posso antever como o receberão os mais próximos), é que percebam o caminho transverso que penosamente percorri e avaliem a pertinência do seu ponto de chegada para a análise que fazem das políticas públicas.

\section{Políticas "normais"}

Para falar de anomalia (estado ou qualidade do desvio acentuado do padrão normal de alguma realidade, anormalidade, irregularidade, aberração) é imprescindível falar primeiro do que não é anômalo, do que é normal. Por isso, para explicar a anomalia da PCT, começo abordando as políticas públicas "normais"; as que não apresentam a anomalia que caracteriza a PCT.

Numa política "normal", atores sociais animados por projetos políticos que são materializados em agendas particulares e dotados de poder acumulado em jogos sociais (políticos) anteriores são capazes de inseri-las na agenda decisória que dá origem à política. Para deixar mais clara essa afirmativa, apresento no Quadro 1 os conceitos que permitem caracterizar as políticas "normais". 


\section{Quadro 1 \\ Caracterização das Políticas "Normais"}

\begin{tabular}{ll}
\hline Ator social & $\begin{array}{l}\text { Pessoa, grupo, organização que participa de um jogo social; possui um projeto político; } \\
\text { controla algum recurso relevante; tem, acumula (ou desacumula) forças no seu decorrer e } \\
\text { pode produzir fatos para viabilizar seu projeto (Matus, 1996). }\end{array}$ \\
\hline $\begin{array}{l}\text { Projeto político do } \\
\text { ator }\end{array}$ & $\begin{array}{l}\text { Conjunto de crenças, interesses, concepçães de mundo, representações do que deve ser } \\
\text { a vida em sociedade, que orientam a ação política dos diferentes atores envolvidos com } \\
\text { uma política (Dagnino, Olvera e Panfichi, 2006) }\end{array}$ \\
\hline $\begin{array}{l}\text { Agenda particular de } \\
\text { um ator }\end{array}$ & $\begin{array}{l}\text { Conjunto de problemas percebidos e enfrentados por ele ao envolver-se com uma } \\
\text { política pública. Numa política "normal”, ela é a materialização do seu projeto político. }\end{array}$ \\
\hline Processo decisório & $\begin{array}{l}\text { Negociação entre os atores defendendo suas agendas particulares com o poder que têm } \\
\text { que irá originar a agenda decisória. }\end{array}$ \\
\hline Agenda decisória & $\begin{array}{l}\text { Originada no processo decisório, ela é a proposta de resolução dos problemas trazidos } \\
\text { pelos atores sociais. É um conjunto de problemas, demandas, assuntos que o governo } \\
\text { (coalizão política que ocupa o poder executivo do aparelho de Estado) seleciona (ou é } \\
\text { forçado a selecionar). Ela é formada pelas agendas particulares dos atores (inclusive pelo } \\
\text { governo, cuja agenda é o programa de governo da coalizão eleita em função da correlação } \\
\text { de forças existente na sociedade). }\end{array}$ \\
\hline
\end{tabular}

Agenda decisória e atores poder relativo dos

Nem todos os problemas que formam as agendas particulares têm a mesma facilidade de fazer parte da agenda decisória e, assim, impor aos que governam a necessidade de atuar sobre eles (Kingdon, 1984; Deubel, 2006). A agenda decisória é uma combinação (média ponderada pelo poder relativo do ator) das agendas particulares de cada ator. Se um ator social for suficientemente forte, ele pode reduzir (ou, no limite, anular) via coerção o poder relativo dos demais e, então, sua participação na formação da agenda decisória. Ou, via convencimento (manipulação) ideológico, fazer com que os demais atores adotem a sua agenda. Nos dois casos, a agenda decisória será, no limite, a agenda particular do ator dominante (primeiro caso) ou hegemônico (segundo), uma vez que passa a existir um "consentimento" dos demais (Gramsci, 1999).

Política pública Originada pela negociação (processo decisório) em torno da agenda decisória, ela é a proposta de resolução dos problemas trazidos pelos atores sociais que nela participam segundo seu poder relativo e que o Estado tem de implementar.

Conflitos

Em tese, em políticas "normais" se originam da diferença existente entre os projetos políticos dos atores envolvidos com uma dada área de política pública. São: 1) abertos, quando em função do poder semelhante dos atores, as diferenças entre suas agendas particulares se explicitam no processo decisório; 2) encobertos, quando o ator dominante consegue, via coerção (velada ou explícita), anular o poder relativo de um mais fraco (dominado), impedindo que sua agenda entre no processo decisório mesmo quando ele participe formalmente do mesmo (Bachrach e Baratz, 1963); 3) latentes (Lukes, 1980), quando o ator, agora hegemônico, consegue via manipulação ideológica fazer com que os demais atores adotem a sua agenda ou, mais precisamente, impedir que o ator dominado seja capaz de conceber sequer uma agenda particular coerente com seu projeto político acerca daquela área de política pública.

Identificação de conflitos latentes
Como não podem ser identificados mediante a simples consideração do processo decisório, exigem uma análise do contexto político e ideológico - dado que os atores dominados não percebem claramente os problemas que os prejudicam e não são capazes de formular uma agenda particular - e das relaçóes de poder - uma vez que não conseguem participar do processo decisório e da formação da agenda decisória para influenciar na orientação da política (Ham e Hill, 1993). 


\section{Políticas anômalas}

Ao contrário do que ocorre quando um dado ator social materializa seu projeto político na sua agenda particular no âmbito de um processo decisório de uma política "normal", quando ele se envolve com uma política anômala, a agenda defendida não é coerente com seu projeto político. Embora participe em outras áreas de política pública enfrentando outros atores na defesa de seus interesses, ele não é capaz de materializá-lo numa agenda particular própria, coerente com seu projeto político, nessa área particular.

Meu argumento é o de que as políticas anômalas se diferenciam das políticas "normais" em que se manifestam conflitos "latentes", isto é, aquelas em que o ator hegemônico consegue, via manipulação ideológi$\mathrm{ca}$, fazer com que o ator dominado adote sua agenda contrariando seu projeto político. Para deixar mais claro o argumento é necessário voltar ao conceito de projeto político - uma vez que o considero insuficiente para a análise de políticas que, como a PCT, considero anômalas - e, em função disso, apresentar um novo conceito - que denominei "modelo cognitivo" que formulei para dar conta do objetivo de analisar a PCT e, espero, políticas similares.

O Quadro 2 apresenta os conceitos que permitem caracterizar as políticas anômalas.

A anomalia, então, implica que atores envolvidos em outras áreas de política e que ali defendem agendas antagônicas, resultantes de projetos políticos irreconciliáveis, por compartilharem em relação à política anômala o mesmo modelo cognitivo, que é o daquela área de política, concordem sistematicamente a respeito de como ela deve ser orientada.

\section{A anomalia da PCT}

A anomalia da PCT pode ser evidenciada ao analisar a PCT dos países avançados, como fiz em Dagnino (2006 e 2007) através de extensa revisão bibliográfica, de maneira a mostrar como atores sociais tão distintos como comunidade de pesquisa, empresários, trabalhadores, movimentos sociais concordam em relação ao modo de orientar a PCT. E, por extensão: 1) como partidos políticos e gover- nos que orientam suas políticas públicas (e, principalmente, as sociais) de modo tão distinto implementam a mesma PCT; 2) como a PCT parece ser uma policy sem politics; 3) como parece estar idelogicamente "blindada" (como ela está tão sujeita a processos de nondecision-making; 4) como conflitos "latentes" e "encobertos" não se convertem em "abertos" no processo decisório da ciência e tecnologia $(\mathrm{C} \& \mathrm{~T}) ; 5)$ como ela está envolta numa "neblina ideológica" de positividade.

A análise que realizei permite explicitar o fato de que seu ator dominante, em todo o mundo, é a comunidade de pesquisa, e que, por isso, seu modelo cognitivo, por ser adotado pelos demais atores envolvidos, é o que tende a orientar a PCT. O que me leva a concentrar neste trabalho minha atenção (ou, talvez seja mais adequado dizer, limitá-la) no ator comunidade de pesquisa e na maneira como ela atua no processo decisório da PCT, fazendo valer o seu modelo cognitivo. Este, como mostrarei, é condicionado pela noção que ela possui sobre a natureza da C\&T. Ou, melhor, num aspecto central dessa noção, que é a não percepção por parte da comunidade de pesquisa dos aspectos e das implicações ideológicas com ela envolvidos.

Para entender a anomalia da PCT é necessário, então, identificar qual a noção ou concepção que possui a comunidade de pesquisa sobre C\&T, ou sobre o que prefiro denominar, por razóes que trato em outros trabalhos (Dagnino, 2008), tecnociência. Isso porque essa concepção, solidamente ancorada em mitos como os assinalados por Sarewitz (1996) e, em particular, naquele que, apoiado em Feenberg (2010) e Lacey (1999), considero fundacional: o da neutralidade e do determinismo da tecnociência (Dagnino, 2008).

Limitar a análise à atuação da comunidade de pesquisa obriga a um distanciamento em relação a outros atores (trabalhadores, empresários etc.) que, animados por seus respectivos projetos políticos, poderiam contrapor-se à comunidade de pesquisa no processo decisório da PCT. Não obstante, o fato de limitar (e refinar) a abordagem sobre a comunidade de pesquisa não inviabilizará a entrada em cena dos dois atores - trabalhadores e empresários, ou classe trabalhadora e classe proprietária - portadores dos projetos políticos que interessa aqui abordar. 


\title{
Quadro 2 \\ Caracterização das Políticas Anômalas
}

\begin{abstract}
Projeto político e Os projetos políticos não se reduzem a estratégias de atuação política, mas veiculam cultura

matrizes culturais mais amplas e transformam o repertório cultural da sociedade (Dagnino, Olvera e Panfichi, 2006). Cultura não é uma esfera, mas uma dimensão de todas as instituiçōes - econômicas sociais e políticas; é um conjunto de práticas materiais que constituem significados, valores e subjetividades. O que implica que as relações de poder entre os atores não possam ser compreendidas sem o reconhecimento de seu caráter "cultural" ativo, na medida em que expressam, produzem e comunicam significados (Alvarez, Dagnino e Escobar, 2000).
\end{abstract}

Modelo Nas políticas anômalas, a atuação do ator não é “informada” pelo seu projeto político, mas pela cognitivo do ator "maneira como ele entende" aquela específica área de política e seu contexto; a essa "maneira" denomino modelo cognitivo do ator. A relação identificada entre projeto político e cultura apontada, embora se aproxime daquela entre projeto político e modelo cognitivo, se diferencia na medida em que, por se referir a um aspecto eminentemente cognitivo do campo mais amplo da cultura, é mais apropriada para a caracterização das políticas anômalas.

Projeto político Um determinado ator, embora possua apenas um projeto político, pode ter tantos modelos e modelos cognitivos cognitivos quantas forem as áreas de política com as quais se envolve. Ao contrário do projeto político, o modelo cognitivo não é um atributo intrínseco do ator, oriundo de sua visão de mundo etc. Sua natureza e eminentemente relacional. O modelo cognitivo de cada ator é condicionado pela sua interação com outros atores no âmbito daquela específica área de política. Ele vai sendo conformado à medida que o ator interage com outros e suas agendas particulares, em processos decisórios. O modelo cognitivo é, então, o conjunto de ideias a partir do qual o ator irá descrever, explicar e prescrever acerca do objeto da política, do seu contexto e participar no processo decisório.

Modelo cognitivo do ator dominante
Como o modelo cognitivo possui um atributo relacional e tem a ver com o nível de conhecimento do ator sobre a área de política, sempre que ela envolver outro ator que tenha sobre ela um conhecimento considerado significativamente maior, o modelo cognitivo deste último ator - cognitivamente dominante - tenderá a influenciar o modelo cognitivo do primeiro. $\mathrm{O}$ caráter de dominante desse ator tende a não estar associado aos fatores de natureza econômica ou política que condicionam seu projeto político, como ocorre em relação às políticas "normais". Não obstante, é razoável pensar que o desvio que o modelo cognitivo do ator terá em relação ao seu projeto político será tanto menor quanto maior for seu conhecimento sobre como funciona a área de política, sobre como a orientação desta o atinge e influencia a satisfação de seus interesses. Inversamente, quanto menor for sua familiaridade com a política em questão e com os assuntos a ela associados, maior tenderá a ser esse desvio. No limite, quando as questôes que centralizam o projeto político do ator dominado estiverem muito distantes dos assuntos abarcados pela área de política, ele tenderá a nela participar de modo praticamente omisso.

Como, muito mais do que o projeto político, o modelo cognitivo de um ator é sensível à influência dos outros, quando o conhecimento do ator dominante tem um caráter de verdade inquestionável, os demais internalizam seu modelo cognitivo, que passa a ser o modelo cognitivo da própria área de política anômala, que emerge da interação entre eles. Por isso, diferentemente do que ocorre nas políticas "normais", em que se manifestam conflitos "latentes", nas políticas anômalas não são as relações de poder econômico ou político que fazem com que o ator dominado não consiga materializar seu projeto político numa agenda particular a ser defendida no processo decisório. Há aqui um poder mais sutil e ainda mais enraizadamente naturalizado por estar a influência do ator dominante investida e revestida de um status cognitivo superior 
Para prosseguir, é conveniente (e necessário) distinguir dois segmentos dentro dessa comunidade. Eles são os que "introduzirão" na análise esses dois atores e seus projetos políticos, ou conjuntos de interesses e valores. A consideração do comportamento desses dois segmentos é o que tornará possível, mediante uma operação de reflexão para dentro da área da PCT, fazer com que "apareçam" no seu decorrer os projetos políticos desses atores, uma vez que eles são adotados e veiculados por cada um desses segmentos.

Para o primeiro, que agrupa a maioria de seus integrantes, a tecnologia é a aplicação da ciência (a "verdade que avança") para produzir mais, melhor, mais barato, poupar tempo e beneficiar a sociedade. Eles costumam dizer que a tecnociência é intrinsecamente boa e verdadeira, mas se a sociedade usá-la sem ética, para o mal, o problema não é deles. Para esse segmento, e este é o aspecto que permite classificá-lo como possuidor de um projeto político de direita, o único agente técnico-produtivo capaz de promover desenvolvimento é a empresa privada que usa a tecnociência que eles ajudam a produzir. Em consequência, acreditam que o conhecimento, para servir à sociedade, tem que passar pela empresa e pelo mercado; tem que ser "comercializável". E se a empresa for inovadora e competitiva, gerará empregos bem pagos, produtos melhores e mais baratos; o empresário obterá mais lucro, investirá mais, os trabalhadores ganharão mais e os consumidores serão mais bem servidos. Enfim, haverá desenvolvimento econômico e social.

A tecnociência, assim, por ser neutra, produzida em busca da verdade e da eficiência, caso esteja submetida ao controle externo e a posterio$r i$ da ética, pode ser usada para satisfazer infinitas necessidades da "sociedade" quaisquer que sejam o substrato e a orientação políticos que num dado momento ela decida implementar.

A participação desse segmento na PCT está centrada em duas ideias: a primeira, de que o Estado deve financiar $\mathrm{P} \& \mathrm{D}$ nas empresas para, dessa forma, promover o desenvolvimento; a segunda, de que, como a tecnociência é boa, verdadeira e universal, temos que emular o que fazem os grupos de pesquisa (ou países) líderes em cada área de conhecimento nos campos da pesquisa e da formação de recursos humanos - e, dado que as eventuais implicaçôes socioeconômicas ou políticas negativas derivam simplesmente de uma falta de ética, temos que nos concentrar nas "áreas de ponta".

Mas há um segundo segmento da comunidade de pesquisa que se opõe a essa maioria replicando: "Sociedade, ética; que nada! Só a revolução e o socialismo resolvem!". Esse ator social, que representa o pensamento de esquerda dentro dessa comunidade, participa com o primeiro, ainda que de modo indistinto (por razóes que trato adiante), do processo decisório que origina a PCT. Seu projeto político está identificado com os interesses da classe trabalhadora: dos que são obrigados a vender sua força de trabalho para os detentores dos meios de produção e, dessa forma, por meio da extração de mais-valia relativa que a tecnociência faculta, possibilitar a reprodução ampliada do capital.

Em função disso, caberia a esse segmento um comportamento coerente com o projeto político que, por serem de esquerda, adotam ou endossam. De fato, caberia a esse segmento - antes mesmo do que à classe trabalhadora com a qual ele se identifica, mas que se encontra muito distanciada dessa área de política - a concepção de uma agenda particular radicalmente diferente daquela identificada com os interesses da empresa privada defendidos pelo primeiro segmento. Em consequência disso, caberia a ele também lutar no âmbito do processo decisório da PCT para fazer valer os interesses daquela classe. Coerentemente com a visão marxista que se situa no núcleo ideológico do pensamento de esquerda, esse ator considera que cada vez mais, no capitalismo, a tecnociência (ou o que denominavam pelo conceito aparentado de forças produtivas) tem servido para elevar a produtividade do processo de trabalho, ou dos trabalhadores, passível de ser apropriada pelos proprietários dos meios de produção, como lucro.

Mas, em função de uma leitura possível da obra de Marx, originada nos anos que sucederam à revolução russa no esforço de transição para o socialismo, tal ator tem uma concepção a respeito da tecnociência, ou das forças produtivas, de natureza determinista e neutra (Feenberg, 2002). Ele pensa, portanto, que na polaridade dialética entre as relações de produção e as forças produtivas, cabe a estas o papel di- 
nâmico e determinante. $\mathrm{Ou}$, ainda, que, como elas se desenvolvem linear e inexoravelmente, sua tensão que ocorre periodicamente com as relações sociais de produção (escravistas, feudais, capitalistas, socialistas), em ciclos de longa duração - terminará levando ao modo de produção comunista.

A maior parte dos autores que criticam a visão da neutralidade não se refere à tecnociência, mas à ciência. Segundo Löwy (2007), ela decorreria da concepção positivista do saber, que tem como uma de suas premissas a ideia de que as ciências da sociedade, como as da natureza, devem limitar-se à observação e à explicação causal dos fenômenos, de forma objetiva, neutra, livre de julgamentos de valor ou ideologias, descartando previamente todas as prenoções e preconceitos. Para Agazzi (1996), ela implica o não envolvimento da ciência com o seu objeto; a independência com relação a preconceitos; a não orientação por interesses particulares; a liberdade de condicionamentos e a indiferença aos empregos que dela se pode fazer. Para Lacey (1999), considerar o juízo científico imparcial implica que os valores sociais não estejam entre os critérios utilizados pelos cientistas na atribuição de juízos. Tampouco as prioridades de pesquisa ou sua orientação devem ser influenciadas por valores de qualquer ordem.

No que respeita ao determinismo tecnológico, a ideia é a de que o desenvolvimento da tecnociência é uma variável independente e universal que determinaria o comportamento de todas as outras variáveis do sistema produtivo e social - como se ela dependesse inteiramente das mudanças e da organização tecnológicas. O desenvolvimento econômico é determinado pelo avanço da tecnociência, e esta é um determinante da estrutura social e a força condutora do progresso social (Dagnino, 2008).

No momento atual, a contradição entre o caráter coletivo e cooperativo da produção levada a cabo pela classe trabalhadora, engendrado pelo estágio de desenvolvimento das forças produtivas, e a apropriação privada dos seus frutos pelos proprietários dos meios de produção tenderia a levar ao socialismo. O que ocorreria quando as condições materiais e objetivas derivadas dessa contradição estivessem suficientemente maduras para que as condiçôes adstritas à ideologia, à consciência de classe dos trabalhadores, consideradas subjetivas, pudessem provocar a "centelha revolucionária"?

Segundo essa concepção, como a tecnociência que hoje oprime a classe trabalhadora é neutra e endogenamente condicionada, no futuro, com a revolução, ela poderá ser por ela apropriada e usada para construir o socialismo.

A participação desse segmento minoritário da comunidade de pesquisa na PCT está centrada em duas ideias cujo fundamento é a concepção da neutralidade e do determinismo. A primeira pode ser assim sintetizada: como o socialismo irá demandar a tecnociência mais avançada que seja possível obter (e a que os cientistas produzirão amanhã será sempre melhor do que a de hoje) para usá-la a fim de satisfazer as necessidades que surgirão do enfrentamento com os interesses capitalistas remanescentes, enquanto não se chega a ela, temos que produzir C\&T de "qualidade" e, para isso, é necessário fazer o que sugerem os cientistas "de ponta”. Afinal, eles é que são os líderes e sabem de tecnociência. A segunda ideia tem a ver com o fato de serem militantes, de estarem trabalhando pela revolução e pelo socialismo, e que, para isso, é importante que os avanços da tecnociência sejam desde agora usados para melhorar a vida dos oprimidos. Afinal, como a tecnociência é neutra, esse uso depende apenas de vontade política para explorar as brechas do sistema.

Resumindo e concluindo, saliento o fato de que esses dois segmentos da comunidade de pesquisa - embora identificados com atores que atuam em outras políticas públicas defendendo agendas com conteúdo oposto, pois emanam de projetos políticos antagônicos - propõem o mesmo tipo de orientação para a PCT. Fato que, justamente, é o que tipifica o caráter anômalo da PCT.

\section{Considerações finais}

A motivação da pesquisa que abarca este trabalho é a observação de que os governos latino-americanos eleitos em oposição ao neoliberalismo - que vêm implementando políticas públicas coerentes com o processo de democratização em curso, para isso arriscando muitas vezes sua governabilidade - 
têm encontrado grande dificuldade em orientar sua PCT num sentido coerente com esse processo. Em outras palavras, e mais especificamente, o objetivo é mostrar que a PCT brasileira, apesar de elaborada por um governo de esquerda, mantém uma orientação neoliberal. Além disso, ainda no plano (ou momento) descritivo da situação existente, é mostrar que a PCT implementada pelo governo de esquerda é ineficaz para aumentar a propensão das empresas realizarem P\&D.

No plano (ou momento) explicativo das origens e condicionantes da situação existente, o objetivo é mostrar que há duas particularidades da PCT brasileira atual. A primeira, sua orientação neoliberal, tem sua origem numa propriedade genérica da PCT - que denominei anomalia apoiando-me em conceitos da análise de políticas para examinar a PCT dos países avançados. A segunda se deve àquilo para que o PLACTS há muito tempo chamou a atenção e que, com base nele e na evidência empírica então inexistente, chamei de atipicidade (específica) da PCT dos países periféricos. Se, por um lado, a atipicidade não foi o foco deste texto - por ela já ter sido explorada em outros trabalhos de colegas filiados ao PLACTS e mesmo de minha autoria -, por outro, abordar a anomalia é, até onde eu posso perceber, relativamente original. Por isso, e por potencializar a crítica que o PLACTS endereça à PCT periférica, estas considerações finais buscam mostrar como se entrelaçam as suas duas propriedades.

Quando o PLACTS formulou sua interpretação sobre o desenvolvimento tecnocientífico latino-americano, a maior parte da esquerda (tradicional) atribuía, com base nas ideias cepalinas e no reformismo do marxismo stalinista, nosso atraso aos obstáculos associados ao imperialismo. Em conjunto com os "resquícios feudais", eles impediam o desenvolvimento de um capitalismo baseado num Estado-nação independente e soberano. Entendia-se a "burguesia nacional" como capaz de nuclear uma aliança com o operariado e outros atores em prol de uma revolução democrático-burguesa que fundasse - como havia ocorrido no então Primeiro Mundo - o capitalismo latino-americano.

A esquerda tradicional, ao privilegiar o imperialismo como o "inimigo principal" e entender a aliança anti-imperialista como a "contradição principal" de nossa sociedade, buscava gerar um clima de mobilização nacional que estimulasse a burguesia industrial nascente a assumir o que era considerado o seu "papel histórico". A minoria que antepunha a essa racionalidade interpretaçóes como a Teoria da Dependência acreditava que a elite local era dependente das elites dos países ricos, de sua cultura e de seus padróes de consumo eurocêntricos; e, como estava a ela subordinada por fortes laços políticos e econômicos, não estava interessada em apostar num caminho de desenvolvimento autônomo.

O PLACTS, alinhado a essa concepção oposta àquela da esquerda tradicional, entendia que, por isso, a "dependência tecnológica" só seria rompida com um "projeto nacional" que contivesse uma "demanda social" por conhecimento tecnocientífico autóctone. Enquanto isso não ocorresse, as elites empresariais, inclusive as nacionais, não teriam por que aproveitar os resultados da pesquisa e os profissionais qualificados gerados pelo complexo público de ensino superior e de pesquisa. Suas demandas em relação a esse complexo não se deviam à intenção de realizar P\&D, limitando-se aos desafios da adaptação e da operação de tecnologia importada (em especial, a incorporada em máquinas, equipamentos e insumos) que o processo de industrialização por substituição de importações trazia consigo.

Contrariando essa avaliação, a comunidade de pesquisa responsável pela elaboração da PCT desde então persegue uma estratégia de sucesso duvidoso, semelhante àquela que adotava a esquerda tradicional. Ao tentar criar um "ambiente de inovação", por meio da criação de mecanismos institucionais e da alocação de recursos para estimular o empresário - considerado "atrasado" e ainda não "convencido" de que a realização de $\mathrm{P} \& \mathrm{D}$ é a melhor maneira de inovar e se tornar competitivo -, a comunidade de pesquisa parece incorrer num equívoco parecido. Ao pretender, no plano tecnocientífico e da dinâmica inovativa, que o empresário tenha um comportamento semelhante ao dos seus congêneres do capitalismo avançado, ela hoje tenta reencenar o enredo análogo (e fracassado) que colocava a burguesia nacional como ator principal, capaz de enfrentar o capital multinacional em prol do desenvolvimento brasileiro. 
O segmento de esquerda da comunidade de pesquisa que elabora a PCT atua como se estivesse ainda no tempo em que alguns admitiam a ideia de que a burguesia nacional viesse a lançar mão dos recursos humanos e materiais locais para forjar uma rota autônoma de desenvolvimento para o país. Preocupado por que isso não está ocorrendo (e dificilmente poderá ocorrer, mantidos os contornos da situação atual), vem reagindo corporativamente. A realidade globalizada do presente, sem tirar de cena, transforma a maneira como se recolocam as questôes do imperialismo e do nacionalismo. Como já não é crível que a debilitada empresa de capital nacional se fortaleça a partir do potencial tecnocientífico do complexo público de ensino e de pesquisa de modo a opor-se às multinacionais no plano interno ou externo, o objetivo da PCT limita-se a estimular a empresa local - considerada brasileira por possuir um CNPJ, independentemente de seu capital ser nacional ou estrangeiro - a aproveitar-se desse potencial.

É como se as ações frente às antigas questões do imperialismo e do nacionalismo devessem se limitar ao âmbito estrito daquele complexo e não se deixar contaminar pelo âmbito privado tecnológico-produtivo em que se situam as empresas nacionais e estrangeiras. Como se a razão de ser da PCT fosse tão somente incrementar nosso potencial passível de ser aquilatado pelo número de artigos publicados e os que aparecem no Science citation index, pela posição no ranking internacional das universidades e sua inclusão entre aquelas de "classe mundial" etc. Mais recentemente, somam-se a essa lista as patentes depositadas, independentemente de quem as deposita, se universidades públicas ou empresas multinacionais, ou se algum dia elas forem de fato licenciadas e utilizadas.

Tudo se passa como se, para avaliar a PCT, fosse suficiente assegurar que ela incremente a "competitividade" da ciência nacional elidindo a preocupação sobre seu objetivo declarado (ainda que a todas luzes irrealizável) de aumentar a competitividade da empresa de capital nacional. Como se a enorme desproporção entre os 30 mil mestres e doutores formados em ciências duras por ano para fazer a P\&D que "deveriam" realizar as empresas e as poucas dezenas que para isso são empregados pudesse resistir a uma crítica, mesmo que interna, ao "círculo vicioso" causado pelo modelo ofertista linear. Isso para não mencionar a crítica externa à baixa relevância da produção científica fomentada e da inadequação do pessoal formado para a solução dos problemas que afligem a maioria da população.

Para concluir, como afirmei que o tratamento que dou ao que chamo de anomalia da PCT é relativamente original, devo ressaltar que, partindo de outra matriz ideológica, autores como Sarewitz (1996) se aproximaram da análise dessas implicações ao apontar a existência dos mitos orientadores da PCT. Adentrando o plano ou momento normativo, embora os assuntos referentes à neutralidade e ao determinismo da tecnociência tenham sido objeto da atenção de autores marxistas críticos à trajetória do stalinismo - como eu mesmo reconheci em leituras que resenhei (Dagnino, $1977 \mathrm{e}$ 2008) -, a sua relação e, em especial, suas implicações para a PCT, não foram por eles tratadas. Como consequência para o plano normativo do processo decisório da C\&T, o segmento de esquerda do seu ator dominante (ou hegemônico, no caso dos países periféricos) não se preocupou em materializar seu projeto político numa agenda que aproximasse a PCT da orientação que, em muitos casos, seus próprios membros propunham para outras políticas públicas.

Talvez a questão relativa à relação CTS ter surgido na América Latina - diferentemente do que ocorreu na Europa e nos Estados Unidos, com um olhar claramente focado e orientado para a PCT (Dagnino, 2008) - explique o surgimento de um "debate implícito" ou inviabilizado, em função de conflitos encobertos para uns e latentes para a maioria do segmento de esquerda da comunidade de pesquisa latino-americana acerca da neutralidade e do determinismo da tecnociência.

Nesse particular, há que enfatizar que, no âmbito do PLACTS, a formulação ainda hoje dominante na crítica à orientação da PCT latino-americana não questiona o caráter pretensamente universal e portanto neutro da tecnociência. Cito Amilcar Herrera, um dos fundadores do PLACTS que melhor tratou dos aspectos políticos relacionados com a PCT, mas que, no entanto, como quase todos os demais, se alinhava com essa formulação. 
Los métodos y el fin de la ciencia son efectivamente universales, y el intercambio continuo y la conexión estrecha con el sistema científico mundial son la única garantía de un nivel de calidad acorde con el que exige el trabajo científico moderno. No puede existir una ciencia "latinoamericana"; lo que sí puede, y debe existir, es una ciencia cuya orientación y objetivos generales estén en armonía con la necesidad de resolver los múltiples problemas que plantea el desarrollo de la región (Herrera, 1971 p. 97).

Ou seja, sua posição, expressa também em outras de suas contribuições (de inestimável valor, destaco, para defender a autonomia tecnológica e científica dos países latino-americanos), era a de que aquela ciência universal poderia ser usada para promover o desenvolvimento da região.

$\mathrm{O}$ único integrante do PLACTS que se diferencia nesse aspecto foi Oscar Varsavsky:

Los medios de difusión de nuestra sociedad ensalzan estas virtudes de la ciencia a su manera, destacando su infalibilidad, su universalidad, presentando a las ciencias físicas como arquetipo y a los investigadores siempre separados del mundo por las paredes de sus laboratorios [...]. Su historia [da ciência] se nos presenta como un desarrollo unilineal, sin alternativas deseables o posibles, con etapas que se dieron en un orden natural y espontáneo y desembocaron forzosamente en la ciencia actual, heredera indiscutible de todo lo hecho... cuya evolución futura es impredecible pero seguramente grandiosa, con tal que nadie interfiera con su motor fundamental: la libertad de investigación (esto último dicho en tono muy solemne) (Varsavsky, 1969, p. 14).

E apontava em seguida, uma das implicaçōes que esse fato, por induzir uma percepção nos participantes da comunidade de pesquisa, tinha para a PCT:

Es natural, pues, que todo aspirante a científico mire con reverencia a esa Meca del Norte, crea que cualquier dirección que allí se indique es progresista y única, acuda a sus templos a perfeccionarse, y una vez recibido su espaldarazo mantenga a su regreso -si regresa- un vínculo más fuerte con ella que con su medio social. Elige alguno de los temas allí en boga y cree que eso es libertad de investigación, como algunos creen que poder elegir entre media docena de diarios es libertad de prensa (Idem, p. 15).

\section{BIBLIOGRAFIA}

AGAZZI, Evandro. (1996), El bien, el mal y la ciencia: las dimensiones éticas en la empresa cientifico-tecnológica. Madri, Tecnos.

ALVAREZ, Sonia E.; DAGNINO, Evelina; ESCOBAR, Arturo. (2000), "O cultural e o político nos movimentos sociais latino-americanos", in Sonia E. Alvarez, Evelina Dagnino e Arturo Escobar (orgs.), Cultura e politica nos movimentos sociais latino-americanos. Belo Horizonte, Editora UFMG.

BACHRACH, P. \& BARATZ, M. S. (1963), "Decisions and nondecisions: an analytical framework". American Political Science Review, 57: 632-642.

DAGNINO, Evelina; OLVERA, Alberto J. \& PANFICHI, Aldo. (2006), "Para uma outra leitura da disputa pela construção democrática na América Latina", in Evelina Dagnino, Alberto J. Olvera e Aldo Panfichi (orgs.), $A$ disputa pela construção democrática na América Latina, São Paulo/Campinas, Paz e Terra/Editora da Unicamp.

DAGNINO, R. (1977), Tecnologia Apropriada: uma alternativa? Dissertação de mestrado. Brasília, UnB.

. (2007), Ciência e tecnologia no Brasil: o processo decisório e a comunidade de pesquisa. Campinas, Editora da Unicamp.

. (2007a), "Os modelos cognitivos das políticas de interação universidade-empresa". Convergência, 45: 84-99.

. (2008), "As trajetórias dos estudos sobre ciência, tecnologia e sociedade e da política 
científica e tecnológica na Ibero-américa”. Revista de Educação em Ciência e Tecnologia, 1 (2): 3-36.

. (2008), Neutralidade da ciência e determinismo tecnológico. Campinas, Editora da Unicamp.

. (2006), "A comunidade de pesquisa dos países avançados e a elaboração da política de ciência e tecnologia". Revista Brasileira de Ciências Sociais, 21 (61): 191-201.

DAGNINO, R.; THOMAS, H. \& DAVYT, A. (1996). "El pensamiento en ciencia, tecnología y sociedad en Latinoamérica: una interpretación política de su trayectoria". Redes, 7: 13-51.

DEUBEL, André-Noël Roth. (2006), Politicas públicas: formulación, implementación y evaluación. Bogotá, Ediciones Aurora.

FEENBERG, A. (2002), Transforming technology: a critical theory revisited. Oxford, Oxford University Press.

. (2010), "O que é a filosofia da tecnologia?", in R. T. Neder, A teoria crítica de Andrew Feenberg: racionalização democrática, poder e tecnologia, Brasília, Observatório do Movimento pela Tecnologia Social na América Latina.

GRAMSCI, A. (1999), Cadernos do cárcere. Vol. 1: Introdução ao estudo da filosofia: a filosofia de Benedetto Croce. Rio de Janeiro, Civilização Brasileira

HAM, C. \& HILL M. (1993), The policy process in the modern capitalist state. Londres, Harvester Wheatsheaf.

HERRERA, A. (1971), Ciencia y Politica en América Latina. Cidade do México, Siglo XXI.

KINGDON, John. (1984), Agendas, alternatives and public policies. Boston, Little Brown Pub.

KUHN, Thomas. (1978), A estrutura das revoluçôes cientificas. São Paulo, Perspectiva.

LACEY, H. (1999). Its science value free? Values and scientific understanding. Londres, Routeledge.

LÖWY, Michael. (2007), As aventuras de Karl Marx contra o Barão de Münchhausen: marxismo e positivismo na sociologia do conhecimento. Trad. Juarez Guimarães e Suzanne Felicie Léwy. São Paulo, Cortez.

LUKES, Steven. (1980), O poder: uma visäo radical. Trad. Vamireh Chacon. Brasília, Editora UnB.
MATUS, Carlos. (1996), Política, planificação e governo. Brasília, Ipea.

SAREWITZ, D. (1996), Frontiers of illusion: science, technology and politics of progress. Filadélfia, Temple University Press.

VARSAVSKY, O. (1969), Ciencia, politica y cientificismo. Buenos Aires, Centro Editor de América Latina. 


\section{A ANOMALIA DA POLÍTICA DE CIÊNCIA E TECNOLOGIA}

\section{Renato Dagnino}

Palavras-chave: Política de ciência e tecnologia; Processo decisório; Neutralidade; Determinismo.

$\mathrm{Na}$ periferia do capitalismo, a política de ciência e tecnologia (PCT) resulta de duas dinâmicas. A primeira, de natureza genérica, é inerente à sua qualidade de política pública e pode ser encontrada "em estado puro" nos países avançados e é responsável pela anomalia de sua PCT. A segunda dinâmica, específica de países periféricos, imprime à PCT uma atipicidade: os atores envolvidos na sua implementação, em virtude do respectivo contexto socioeconômico e político, manifestam comportamentos sistematicamente divergentes daqueles observados e modelizados nos países avançados. O artigo argumenta que tal anomalia tem sua origem nos mitos da neutralidade e do determinismo da tecnociência que a acompanham desde quando o Estado decide influenciar a mudança tecnológica e a formação de pesquisadores.

\section{THE ANOMALY OF THE SCIENCE AND TECHNOLOGY POLICY}

\section{Renato Dagnino}

Keywords: Science and technology policy; Decision making; Neutrality; Determinism.

On the periphery of capitalism, Science and Technology Policy (STP) results from the combination of two dynamics: one inherent to the STP as a public policy, and other due to the peripheral condition. The first, generic, can be found "in pure form" in advanced countries and is responsible for the STP anomaly. The second, specific to peripheral countries, gives to their STPs an atypical character. Due to the peripheral socioeconomic and political context, the actors involved in their implementation manifest behaviors systematically different from those observed in (and modeled by) advanced countries. Inserted in an effort to understand the peripheral STP, this paper argues that the anomaly foundation is the myth of Neutrality and Determinism of Technoscience that orients it since when the State decides to influence technological change and research.

\section{LANOMALIE POLITIQUE DE LA SCIENCE ET DE LA TECHNOLOGIE}

\section{Renato Dagnino}

Mots-clés: Politique des sciences et de la technologie; Processus décisoire; Neutralité; Déterminisme.

À la périphérie du capitalisme, la politique des sciences et de la technologie (PST) est le fruit de deux dynamiques. La première, de nature générique, est inhérente à sa qualité de politique publique et peut être retrouvée "en état pur" dans les pays développés et est responsable de l'anomalie de sa PST. La seconde dynamique, spécifique aux pays périphériques, imprime à la PST un caractère atypique: les acteurs impliqués dans sa mise en œuvre manifestent, en vertu du contexte socio-économique et politique, des comportements systématiquement divergents de ceux observés et modélisés dans les pays développés. L'article défend qu'une telle anomalie a son origine dans les mythes de la neutralité et du déterminisme de la tecno-science qui l'accompagnent depuis l'époque où l'État a décidé d'influencer le changement technologique et la formation des chercheurs. 